University of Windsor

Scholarship at UWindsor

2018

\title{
Relative effectiveness of mindfulness and cognitive behavioral interventions for anxiety disorders: Meta-analytic review
}

\author{
Samina K. Singh \\ University of Windsor \\ Kevin M. Gorey \\ University of Windsor
}

Follow this and additional works at: https://scholar.uwindsor.ca/socialworkpub

Part of the Alternative and Complementary Medicine Commons, Cognitive Behavioral Therapy

Commons, Counseling Commons, Mental Disorders Commons, Other Nursing Commons, Other

Psychiatry and Psychology Commons, Psychiatric and Mental Health Commons, Psychoanalysis and

Psychotherapy Commons, Psychology Commons, and the Social Work Commons

\section{Recommended Citation}

Singh, Samina K. and Gorey, Kevin M.. (2018). Relative effectiveness of mindfulness and cognitive behavioral interventions for anxiety disorders: Meta-analytic review. Social Work in Mental Health, 16 (2), 238-251.

https://scholar.uwindsor.ca/socialworkpub/58

This Article is brought to you for free and open access by the School of Social Work at Scholarship at UWindsor. It has been accepted for inclusion in Social Work Publications by an authorized administrator of Scholarship at UWindsor. For more information, please contact scholarship@uwindsor.ca. 


\section{Relative effectiveness of mindfulness and cognitive behavioral interventions for anxiety disorders: Meta-analytic review}

\section{Samina K. Singh \& Kevin M. Gorey}

To cite this article: Samina K. Singh \& Kevin M. Gorey (2018) Relative effectiveness of mindfulness and cognitive behavioral interventions for anxiety disorders: Meta-analytic review, Social Work in Mental Health, 16:2, 238-251, DOI: 10.1080/15332985.2017.1373266

To link to this article: https://doi.org/10.1080/15332985.2017.1373266

Accepted author version posted online: 22

Sep 2017.

Published online: 03 Nov 2017.

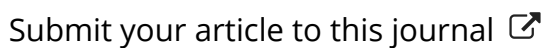

Џلll Article views: 189

Q View related articles $\asymp$

View Crossmark data $\nearrow$ 


\title{
Relative effectiveness of mindfulness and cognitive behavioral interventions for anxiety disorders: Meta-analytic review
}

\author{
Samina K. Singh, BSW (10) ${ }^{\mathrm{a}, \mathrm{b}}$ and Kevin M. Gorey, PhD, MSW (10)

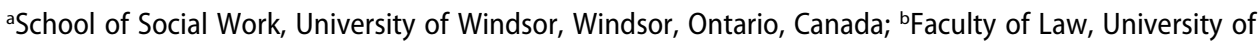 \\ Windsor, Windsor, Ontario, Canada
}

\begin{abstract}
Increasingly popular mindfulness intervention innovations seem demonstrably effective in alleviating anxiety among people with anxiety disorders. However, the basis of such primary and synthetic evidence has, for the most part, been comparisons with non-active comparison conditions such as waiting lists. The longest-standing and strongest evidence-informed practices in this field have been cognitive behavioral interventions (CBI). This meta-analysis synthesized evidence from nine randomized trials of the relative effectiveness of mindfulness interventions compared to CBIs (i.e., active control groups) in treating anxiety disorders. The sample-weighted synthesis found no statistically or practically significant differences between the two groups on anxiety alleviation: Cohen's $d=$ - $0.02(95 \%$ confidence interval $=-0.16,0.12)$. Both groups enjoyed large clinical benefits. However, because mindfulness methods may require less professional training and take less time for both workers and clients to master, they are probably less expensive to provide. As they are probably less expensive, but equally effective, it seems that, in a cost-beneficial sense, mindfulness interventions may be more practically effective. These review-generated meta-analytic findings and inferences may be best thought of as developed hypotheses for future research testing. These and other future research needs are discussed.
\end{abstract}

\section{KEYWORDS}

Anxiety disorders; cognitive behavioral interventions; meta-analysis; mindfulness; social work practice

Anxiety can be an adaptive emotion that helps one prepare for possible threats. It only becomes maladaptive when the anxiety is chronic, excessive, and uncontrollable (Beidel, Bulik, Stanley, \& Anne, 2012; Butcher, Mineka, \& Hooley, 2010). These are often associated with work and family life stresses, financial strains, or illnesses (Butcher et al., 2010). With interacting personal and environment determinants, problems with anxiety usually begin in childhood or adolescence (Beidel et al., 2012; Kroenke, Spitzer, Williams, Monahan, \& Löwe, 2007). There are 12 categories of anxiety disorders in the fifth edition of the Diagnostic and Statistical Manual of Mental Disorders, the 
most common of which are generalized anxiety disorder, panic disorder, and social anxiety disorder (American Psychiatric Association, 2013; Kroenke et al., 2007). Their commonalities are three-fold: physical symptoms (e.g., increased heart rate, sweating, feeling tense), negative cognitions or subjective distress, and behavioral symptoms such as avoidance (Beidel et al., 2012). One can easily intuit the relevance to social work with the relatively greater stresses and strains in the lives of those we often aim to serve, for example, those living in poverty. And even if anxiety is not the primary target of our work one can clearly see how anxiety might exacerbate other personal, familial or even social-structural challenges and could become a robust barrier to our most effective work with such diverse clients.

Anxiety disorders are a public concern as well. In aggregate, they are the second most common mental disorder seen in primary care settings (Ansseau et al., 2004; Kroenke et al., 2007). A systematic review of 50 studies by Somers, Goldner, Waraich, and Hsu (2006) estimated the lifetime prevalence of any anxiety disorder to be $17 \%$. In other words, one of every six people is likely to have an anxiety disorder at some time during their lives. Moreover, many of them (57\%) will have a comorbid mental disorder, most likely another anxiety disorder or depression (Beidel et al., 2012). Anxiety has negative consequences for individuals and society. Woodward and Fergusson (2001) found that people living with anxiety have increased risks of academic underachievement, early parenthood, depression, substance abuse, and suicidal behaviors. Given such interrelated sequela, it is not surprising that anxiety disorders also detrimentally affect society through such socioeconomic forces as decreased productivity and increased use of health care services (Wittchen, 2002). In the United States alone, the cost of anxiety disorders is estimated to be more than 40 billion dollars per year (Kroenke et al., 2007).

The most common treatments for anxiety disorders are cognitive behavioral interventions (CBIs). CBIs were first developed by Aaron Beck and his colleagues (Beck, Rush, Shaw, \& Emery, 1979) for the treatment of depression. Many studies, however, have found CBIs to be effective treatments of anxiety disorders (e.g., Barlow, Allen, \& Basden, 2007; DeRubeis \& CritsChristoph, 1998). The average recovery rate, indicative of clinically significant anxiety alleviation, for CBIs across all anxiety disorders is about 70\% (Barlow, Wright, Sheasby, Turner, \& Hainsworth, 2002; Beidel et al., 2012). CBIs are based on the idea that cognitive and behavioral factors influence emotional dominance (Beck \& Emery, 2005). Cognitive-behavioral therapists believe that problems result from biased processing of stimuli. These biases distort individuals' experiences and create realities that are filled with cognitive errors (Beck \& Emery, 2005). The primary goal of CBIs is to reduce anxiety by identifying cognitive distortions and replacing them with adaptive ones. There are numerous types of CBI, the most common of which is cognitive restructuring. 
Mindfulness is a new form of treatment that has become increasingly popular over the past decade or so. However, the concept of mindfulness is over 2000 years old. It originates from Buddhist traditions, where it is important in the practice of attaining enlightenment (Snyder \& Lopez, 2011). Mindfulness was first introduced into Western medicine by Kabat-Zinn (2003) during the 1980s for the management of chronic pain. It was found to be successful and expanded to other disorders, such as depression and anxiety during the 1990s. The definition of mindfulness involves the awareness that emerges through purposefully paying attention to the present moment and, without prejudice, observing the unfolding experience a moment at a time (Snyder \& Lopez, 2011). Mindfulness interventions are based on learning skills that allow one to disengage from dysfunctional cognitive routines by paying attention to the present moment on purpose and without judgement (KabatZinn, 2003; Segal, Williams, \& Teasdale, 2002). There are numerous types of mindfulness interventions: mindfulness-based cognitive therapy, mindfulnessbased stress reduction, acceptance therapy, yoga-based therapy, relaxation therapy, and others.

Mindfulness interventions have been increasingly integrated into mental and physical health practices over the past 10 to 15 years. Developmental studies have demonstrated their effectiveness, but have typically used comparisons to non-active comparison or control groups such as those composed of participants on waiting lists (Craigie, Rees, Marsh, \& Nathan, 2008; Hoge et al., 2013; Houghton, 2008). Several generally relevant systematic reviews and meta-analyses have been accomplished in diverse contexts, ranging from social work practice and allied mental health, including psychological practice to primary care and diverse specialized medical practices (De Vibe, Bjørndal, Tipton, Hammerstrøm, \& Kowalski, 2012; Gotink et al., 2015; Rhodes, 2014). They also consistently found that mindfulness interventions could largely alleviate the symptoms of anxiety disorders and their damaging sequela, but they were also most typically based on non-active comparison conditions. Recent narrative and systematic reviews have recorded contemporary inroads of mindfulness interventions into diverse social work fields of practice from, for example, practices with addicts to culturally adapted practices with Hispanic immigrants (Escobar \& Gorey, 2017; Garland, 2013; Trowbridge \& Lawson, 2016). Garland concluded that they are a "natural fit," mindfulness methods being highly congruent with strengthsbased, empowerment methods of social work practice.

This synthetic study is a more controlled meta-analysis of the effectiveness of mindfulness interventions compared to CBIs (i.e., active control groups) in treating anxiety disorders. In that mindfulness innovations will be compared to this field's most prevalently offered CBIs we think that this synthesis will begin to better inform cost-benefit decisions than previous ones. Given previous primary and synthetic research suggestions about the general 
effectiveness of mindfulness interventions as well as their seeming colloquial and professional popularity, we explored the hypothesis that mindfulness interventions are more effective than CBIs for people with anxiety disorders.

\section{Methods}

\section{Sample of studies}

Searches of the following research databases were conducted until March of 2017: Social Work Abstracts, Social Service Abstracts, PsycINFO, PubMed, Web of Science, CINAHL Complete, Cochrane Library, ProQuest Dissertations and Theses and Google Scholar (De Smidt \& Gorey, 1997; Torgerson, 2006). The following keywords were used to search the databases (cognitive behav* or cognitive-behav ${ }^{\star}$ therapy, treatment or intervention, CBT, or CBI) and (mindfulness or mindfulness-based stress reduction or MBSR or mindfulness-based cognitive therapy or MBCT) and (anxi ${ }^{\star}$ or anxiety disorder or generalized anxiety disorder or GAD or panic attack or panic disorder or PD or social anxiety or social anxiety disorder or SAD or separation anxiety or phobia) and (experiment or randomized controlled trial or RCT) (see table footnotes for explanation of acronyms). Nine RCTs that independently compared mindfulness with CBIs immediately post-intervention on a validated measure of anxiety were selected. They are noted in the references section with an asterisk. RCTs were selected for their high internal validity. Immediate post-intervention data were analyzed because all the studies made such reports, while only a few made longer follow-up reports.

\section{Meta-analysis}

Findings of the nine experimental studies were synthesized by means of a meta-analysis. Meta-analyses use quantitative and standardized measures of intervention effect size, allowing one to move beyond simplistic statistical questions such as whether a given intervention seems to work. Effect size metrics allow one to estimate how much better a new treatment innovation is than an established or more traditional treatment in achieving a desired goal, in this instance, anxiety alleviation (Coe, 2002: Cooper, Hedges, \& Valentine, 2009). They tend to put the focus on practical, clinical or policy, significance rather than on mere statistical significance.

Cohen's (1988) $d$-index served as this study's central meta-analytic effect size statistic. Allowing for the translation of the primary studies' diverse statistical outcomes into a common metric, it aids in making between-study comparisons. It can be calculated directly from study group means and standard deviations ( $\left.d=M_{1}-M_{2} /\left(S D_{1}+S D_{2}\right) / 2\right)$ or can be derived from a host of parametric or nonparametric statistics (chi-square $\left[\chi^{2}\right], t$-test, $F$-ratio and others; Chinn, 2000; 
Cooper, 2017). To aid practical interpretations, clinically and statistically significant $d s$ were converted to Cohen's $U_{3}$ statistics (1988). $U_{3}$ is intuitively appealing because it compares all the participants' scores in one study group with the median or typical participant's score in another. It practically assists interpretations by putting the emphasis on people rather than on statistics. For example, a hypothetically supportive study $d$ of 1.00 is equivalent to a $U_{3}$ of $84 \%$. If it resulted from the post-test comparison of respective groups of clients who experienced mindfulness or CBIs on a continuous measure of anxiety, it could be interpreted as follows; More than $80 \%$ or approximately 17 of every 20 of the clients who experienced the mindfulness intervention scored lower on the anxiety measure at post-test than did the typical client in the CBI control group. Given adequate experimental samples, one can assume that the groups were equivalent on anxiety at pre-test. It should be noted that hypothetically supportive and counter-hypothetical effects will be reported, respectively, as positive and negative $d s$. Fixed individual study effects $(d s)$ were weighted by their inverse variances so that larger, more precise studies influenced the synthesis more than smaller studies and the pooled $d$ 's combined statistical significance was estimated with a 95\% confidence interval [CI] (Chinn, 2000; Cooper, 2017; Greenland, 1987). A 95\% CI that includes the null value of 0.00 indicates that the aggregate difference between the two study groups was not statistically significant.

The effect distribution was then tested for heterogeneity with Cochran's $Q$ statistic (Cooper, 2017; Fleiss, Levin, \& Paik, 2003; Hedges, 1994). With a chi square $\left(\chi^{2}\right)$ distribution, it tests if the variability of effects is greater than expected by sampling error. Potential sources of variability or effect moderations were explored. One such source, the difference between published and unpublished study effects, an indicator of potential publication bias, was tested with Cochran's $Q_{\mathrm{b}}$ statistic. It is a function of $Q$ and again, distributed as $\chi^{2}$. Outliers were also explored. For instance, Lauren Drvaric (2013) studied very brief, one-hour interventions. Her estimated effect was compared to that of the eight studies of much more extended interventions. Also, there was only one study of mindfulness-based cognitive therapy which incorporates aspects of mindfulness and CBIs (Piet, Hougaard, Hecksher, \& Rosenberg, 2010). Its effect was compared to that of the eight studies of mindfulness-specific interventions. All analyses were replicated with $100 \%$ agreement between two meta-analysts, this study's co-authors.

\section{Results}

\section{Sample description}

Characteristics of the 739 participants and nine randomized trials are displayed in Table 1. First, the trials may not be very well controlled as the 


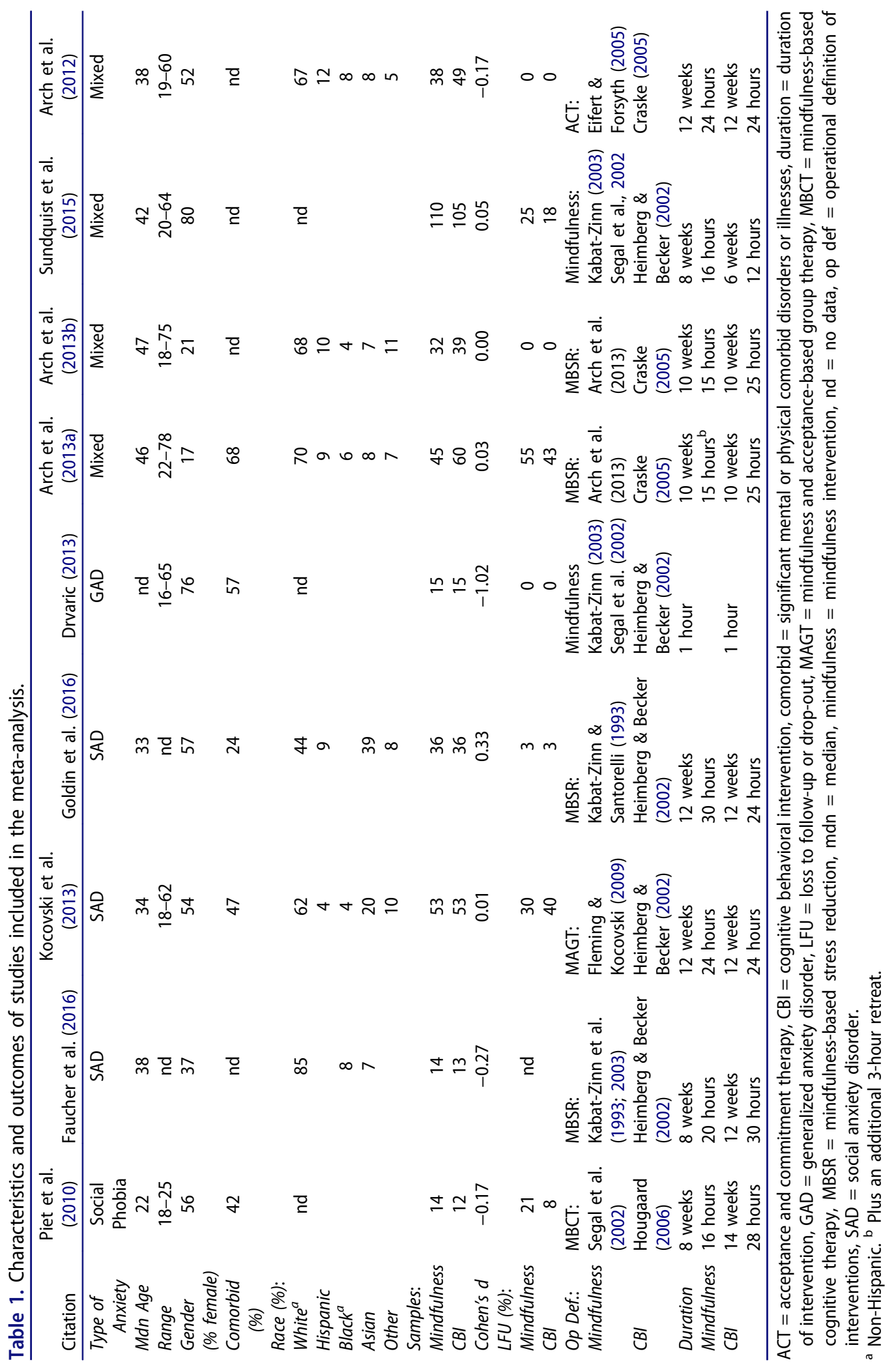


median or most typical mindfulness intervention only had 36 completers, the typical CBI, 39. Moreover, there seemed to have been significant losses of study participants in three or four of the studies. Next, most of them were adults, ranging from 18 to 65 or so, tending to cluster most between 35 and 45. One study was of younger adults between the ages of 18 and 25 . Five studies had gender-balanced samples, while two studies each had samples dominated by women or men. The aggregate sample had slightly more women than men (54\% vs. $46 \%$ ). When reported, nearly three-quarters of the study completers were non-Hispanic white people. In nearly all instances any minority ethnic/racial subsample was $10 \%$ or less of its study total. One study focused on people with generalized anxiety disorders, four on social anxiety, and the others included people with a variety of anxiety disorders. Finally, the five studies reporting comorbidities suggested that about half of their participants had such mental or physical disorders or illnesses.

Seven of the studies were accomplished in North America, four in the United States, three in Canada, and two in Northern Europe (Denmark and Sweden). All were quite contemporary, published between 2010 and 2016. As anticipated the mindfulness interventions were diverse, four used mindfulness-based stress reduction. The other five used different mindfulness methods, ranging from mindfulness-based cognitive therapy to acceptance and commitment therapy or mindfulness and acceptance-based group therapy. In fact, seven were group and two were individual-level interventions. The CBI groups consisted of six to eight participants, while the mindfulness based groups consisted of twelve to fourteen participants. Similarly, the CBIs were based on treatment manuals produced by three different practice-research groups. Except for the previously mentioned outlier, intervention durations ranged from 15 to 30 total hours over 8 to 14 weeks. Finally, only three studies followed their participants beyond the immediate three-month, postintervention period.

\section{Meta-analytic findings}

In Table 1 , note that four of the study effect sizes or Cohen's $d$-indexes were zero or very close to zero and four others were quite small. The sampleweighted $d$ was also essentially zero $-0.02(95 \% \mathrm{CI}=-0.16,0.12)$. The fact that the $95 \%$ CI includes the null value of 0.00 indicates that the aggregated difference between all the mindfulness and CBI participants in these nine studies was not statistically significant. Moreover, the study effects were no more heterogeneous than could be explained by sampling error; $\chi^{2}(8)=9.94$, NS. Therefore, our hypothesis that mindfulness interventions may be more effective than CBIs in alleviating anxiety among people with anxiety disorders was not supported. In fact, the two types of interventions seemed equally effective. The recovery or remission rates for both clustered around $75 \%$. The 
outlying study of one-hour interventions $\left(d=-1.02, U_{3}=85 \%\right)$ did have a counter-hypothetical effect that was significantly different than that of the eight other studies (weight $d=-0.01$ ); $\chi^{2}(1)=6.40, p<.05$. Hence, for this very brief intervention $85 \%$ of the CBI participants scored lower on anxiety at post-test than did the typical mindfulness intervention participant. No other characteristic of the participants, contexts, or research designs, outlying or otherwise, significantly moderated the overall meta-analytic effect or mindfulness-CBI difference.

\section{Discussion}

This meta-analysis synthesized evidence from nine randomized trials of mindfulness and CBIs for work with people with anxiety disorders. Based on their prevalence, popularity, and strong suggestions of relative effectiveness, we hypothesized that mindfulness methods are more effective than CBIs. However, the meta-analytic findings, practical and statistical, indicated that mindfulness interventions were not more effective than CBIs. In fact, both sets of intervention methods seemed to be quite effective in alleviating anxiety. This "nonsignificant" between-group synthetic finding, however, may ultimately be quite significant in clinical and policy matters. Furthermore, our central null finding, in concert with our finding of no significant difference between the outcomes of articles published in peerreviewed journals and an unpublished thesis effectively rules out publication bias as a potent confound in this meta-analysis.

Mindfulness methods have been shown to be more cost effective than other treatment methods in other clinical contexts (Hofmann \& DiBartolo, 2014; Knight, Bean, Wilton, \& Lin, 2015). In this context, because they tend to have a more generalist stance and a somewhat less task-centered focus, mindfulness methods may require less professional and field training to provide effectively (Snyder \& Lopez, 2011). As mindfulness techniques probably take less time and training to master than cognitive behavioral techniques, mindfulness interventions are probably also less expensive to provide. Furthermore, they may be easier to incorporate into clients' daily lives as there are diverse ways to practice mindfulness techniques in very brief sessions of only ten minutes or so (Chiesa \& Serretti, 2010; Moore, Gruber, Derose, \& Malinowski, 2012). Therefore, on cost-effectiveness or efficiency one could fairly conclude that mindfulness interventions are more effective than CBIs. As they are probably less expensive, but equally effective, it seems that, in a cost-beneficial sense, mindfulness interventions may be more practically effective (Piet et al., 2010). It is important to note though that these meta-analytic findings, as are all such review-generated findings, are correlational and tentative. At this point they may be best thought of as developed hypotheses for future research testing. 


\section{Future direction}

One study included in this meta-analysis was distinctly counter-hypothetical, that is, its cognitive behavioral participants did much better than its mindfulness participants. It was a tentative outlying study of mere one-hour interventions that had only 15 participants per study group. Still its finding stood in provocative contrast to our central meta-analytic finding. Frankly, we are not certain why such a brief CBI would be more effective than a similarly brief mindfulness intervention. Perhaps there is a steeper initial client learning curve for certain Buddhist and Eastern philosophy-based, mindfulness methods in the West. Narrative study of the experiences of such clients will probably be needed to advance our practical knowledge about which specific methods, cognitive behavioral or mindfulness, are most likely to work best in relatively brief to more extended intervention contexts.

The major limitation of the studies included in this meta-analysis was their small samples. Typical study group samples of 35 to 40 suggested that this field's studies have been generally under-powered. Future randomized trials ought to be better controlled, statistically powered by ample samples sufficient to allow the detection of modest, but clinically significant, betweengroup differences with confidence. For example, using standard statistical criteria (1-tailed $\alpha=0.05$; power $_{1-\beta}=0.80$ ), samples of between 150 and 300 mindfulness and CBI participants each would be required to detect differences characterized by $d s$ of 0.20 to 0.30 (Faul, Erdfelder, Lang, \& Buchner, 2007; Fleiss et al., 2003). Such larger trials also ought to be amply funded, allowing for the staffing, training and procedural supports needed to ensure high completion rates and longer term, post-intervention follow-up periods.

Relatedly, this synthetic study lacked the meta-analytic power necessary to confidently test mindfulness-CBI differences much beyond an overall main intervention effect. As described in the introduction, there are numerous types of mindfulness interventions not to mention CBI variations. For example, mindfulness interventions in this field range from the incorporation of various mindfulness methods with cognitive behavioral methods to yogabased therapies. Yet there are not enough individual or comparative studies of specific mindfulness methods to be able to confidently synthesize or metaanalytically test them. Studies of such diverse mindfulness interventions compared to similarly diverse CBIs will be needed in this field's next generation. A research agenda comprised of a series of mindfulness-CBI comparative studies, preferentially randomized controlled trials, will help us to better understand what works best with whom, and under what circumstances. Furthermore, this field has yet to systematically pose and answer questions about the importance of gender, ethnicity, specific diagnoses and comorbidities. If future studies included ample samples of women and men, diverse peoples of color and non-Hispanic white people, people with specific 
anxiety disorders and other conditions such as depression and substance abuse disorders, and reported subsample-specific findings, that would go a long way toward advancing this aggregate field's validity, both internal and external.

Finally, though the client participants in the nine trials and the interventions were generally well described, the therapists were not. Psychologists were most prevalent, but social workers and psychiatrists, all ranging from "inexperienced students" to "experienced therapists" were also represented. Beyond that we know little about their general training or trial-specific training in cognitive behavioral or mindfulness methods. But consistent with our developing hypothesis about the relative efficiency of mindfulness interventions, one study claimed effective mindfulness training over only one week, and another reported "certified yoga instructor" as its trained therapist criterion, a credential gained far more expeditiously than a professional degree in social work, psychology, or medicine (Faucher, Koszycki, Bradwejn, Merali, \& Bielajew, 2016; Sundquist et al., 2015). All of the trials used treatment manuals and the majority used supervision as intervention fidelity assurances, but only three used standardized fidelity measures to assess therapists' behaviors. Those inferred a high degree of treatment integrity. We do not think our synthesis fatally confounded by this lack-six studies using non-standardized or no fidelity measures versus the three that did-as it did not significantly moderate the overall meta-analytic effect. But given this potential limitation we cannot completely rule-out therapy contamination as a possible alternative explanation for our synthetic findings. Other syntheses of more than 100 studies have noted this limitation across social work and allied mental health interventions and suggested the consistent use of validated treatment fidelity measures in future research (Maynard, Peters, Vaughn, \& Sarteschi, 2013; Naleppa \& Cagle, 2010). We concur. Additionally, we think that qualitative study of therapists, helping us to better understand their rich narrative experiences, would complement the confident, but often reduced knowledge gained from RCTs. Such mixed-methods studies could aid in planning this field's future research agenda, at once testing existing theories, while developing perhaps more eclectic theories for future research testing.

\section{Conclusions}

Our central finding was that mindfulness and cognitive behavioral intervention methods are equally and largely effective for work with people with anxiety disorders. However, because mindfulness methods are probably less expensive in certain contexts, in a cost-beneficial sense, they may be more practically effective in those contexts. These review-generated meta-analytic 
findings are best thought of as developed hypotheses for future research testing.

\section{ORCID}

Samina K. Singh (10) http://orcid.org/0000-0001-5213-3022

Kevin M. Gorey (D) http://orcid.org/0000-0003-1870-6549

\section{References}

* Studies included in the meta-analysis.

American Psychiatric Association. (2013). Diagnostic and statistical manual of mental disorders (5th ed., DSM-5). Arlington, VA: Author.

Ansseau, M., Dierick, M., Buntinkx, F., Cnockaert, P., De Smedt, J., Van Den Haute, M., \& Vander Mijnsbrugge, D. (2004). High prevalence of mental disorders in primary care. Journal of Affective Disorders, 78(1), 49-55. 10.1016/S0165-0327(02)00219-7

* Arch, J. J., \& Ayers, C. R. (2013a). Which treatment worked better for whom? Moderators of group cognitive behavioral therapy versus adapted mindfulness based stress reduction for anxiety disorders. Behaviour Research and Therapy, 51(8), 434-442. 10.1016/j. brat.2013.04.004

* Arch, J. J., Ayers, C. R., Baker, A., Almklov, E., Dean, D. J., \& Craske, M. G. (2013b). Randomized clinical trial of adapted mindfulness-based stress reduction versus group cognitive behavioral therapy for heterogeneous anxiety disorders. Behaviour Research and Therapy, 51(4), 185-196. 10.1016/j.brat.2013.01.003

* Arch, J. J., Eifert, G. H., Davies, C., Vilardaga, J. C. P., Rose, R. D., \& Craske, M. G. (2012). Randomized clinical trial of cognitive behavioral therapy (CBT) versus acceptance and commitment therapy (ACT) for mixed anxiety disorders. Journal of Consulting and Clinical Psychology, 80(5), 750-765. 10.1037/a0028310

Barlow, D. H., Allen, L. B., \& Basden, S. L. (2007). Psychological treatments for panic disorders, phobias, and generalized anxiety disorders. In P. E. Nathan, \& J. M. Gorman (Eds.), A guide to treatments that work (pp. 351-394). New York: Oxford University Press.

Barlow, J. H., Wright, C. C., Sheasby, J., Turner, A. P., \& Hainsworth, J. (2002). Selfmanagement approaches for people with chronic conditions: A review. Patient Education and Counseling, 48(2), 177-187.

Beck, A. T., \& Emery, G. (2005). Anxiety disorders and phobias: A cognitive perspective (15th ed.). New York, NY: Basic Books

Beck, A. T., Rush, A. J., Shaw, B. F., \& Emery, G. (1979). Cognitive therapy of depression. New York, NY: Guilford Press.

Beidel, D. C., Bulik, C. M., Stanley, M. A., \& Anne, M. (2012). Abnormal psychology (2nd ed.). Boston, MA: Pearson.

Butcher, J., Mineka, J., \& Hooley, J. M. (2010). Abnormal psychology (14th ed.). Boston, MA: Allyn \& Bacon.

Chiesa, A., \& Serretti, A. (2010). A systematic review of neurobiological and clinical features of mindfulness meditations. Psychological Medicine, 40(8), 1239-1252. 10.1017/ S0033291709991747

Chinn, S. (2000). A simple method for converting an odds ratio to effect size for use in metaanalysis. Statistics in Medicine, 19(22), 3127-3131. 10.1002/(ISSN)1097-0258 
Coe, R. (2002, September). It's the effect size, stupid: What effect size is and why it is important. Paper presented at the annual conference of the British Educational Research Association, Exeter, England.

Cohen, J. (1988). Statistical power analysis for the behavioral sciences (2nd ed.). Hillsdale, NJ: Erlbaum.

Cooper, H. (2017). Research synthesis and meta-analysis: A step-by-step approach (5th ed.). Thousand Oaks, CA: Sage.

Cooper, H., Hedges, L. V., \& Valentine, J. C. (Eds.) (2009). The handbook of research synthesis and meta-analysis. New York, NY: Russell Sage Foundation.

Craigie, M. A., Rees, C. S., Marsh, A., \& Nathan, P. (2008). Mindfulness-based cognitive therapy for generalized anxiety disorder: A preliminary evaluation. Behavioural and Cognitive Psychotherapy, 36(5), 553-568. 10.1017/S135246580800458X

Craske, M. G. (2005). Cognitive-behavioral treatment of anxiety disorders. (Unpublished manuscript).

DeRubeis, R. J., \& Crits-Christoph, P. (1998). Empirically supported individual and group psychological treatments for adult mental disorders. Journal of Consulting and Clinical Psychology, 66(1), 37-52. 10.1037/0022-006X.66.1.37

De Smidt, G. A., \& Gorey, K. M. (1997). Unpublished social work research: Systematic replication of a recent meta-analysis of published intervention effectiveness research. Social Work Research, 21(1), 58-62. 10.1093/swr/21.1.58

De Vibe, M., Bjørndal, A., Tipton, E., Hammerstrøm, K. T., \& Kowalski, K. (2012). Mindfulness based stress reduction (MBSR) for improving health, quality of life and social functioning in adults. Campbell Systematic Reviews, 8, 3.

* Drvaric, L. (2013). Mindfulness vs. cognitive restructuring skills in anxiety (Unpublished master's thesis). McMaster University, Hamilton, Ontario.

Eifert, G. H., \& Forsyth, J. P. (2005). Acceptance and commitment therapy for anxiety disorders: A practitioner's treatment guide to using mindfulness, acceptance, and valuesbased behavior change strategies. New York, NY: Guilford Press.

Escobar, K. M., \& Gorey, K. M. (2017). Cognitive-behavioral interventions for anxiety disorders: Rapid review suggestion of larger effects among Hispanic than non-Hispanic white people. Manuscript submitted for publication.

* Faucher, J., Koszycki, D., Bradwejn, J., Merali, Z., \& Bielajew, C. (2016). Effects of CBT versus MBSR treatment on social stress reactions in social anxiety disorder. Mindfulness, 7 (2), 514-526. 10.1007/s12671-015-0486-4

Faul, F., Erdfelder, E., Lang, A. G., \& Buchner, A. (2007). GPower 3: A flexible statistical power analysis program for the social, behavioral, and biomedical sciences. Behavioral Research Methods, 39 (2), 175-191. 10.3758/BF03193146

Fleiss, J. L., Levin, B., \& Paik, M. C. (2003). Statistical methods for rates and proportions (3rd ed.). Hoboken, NJ: Wiley.

Fleming, J., \& Kocovski, N. L. (2009). Mindfulness and acceptance-based group therapy for social anxiety disorder: A treatment manual. Centre for Addiction and Mental Health, University of Toronto and Ryerson University, Toronto, ON and Wilfrid Laurier University, Waterloo, ON.

Garland, E. L. (2013). Mindfulness research in social work: Conceptual and methodological recommendations. Social Work Research, 37(4), 439-448. 10.1093/swr/svt038

* Goldin, P. R., Morrison, A., Jazaieri, H., Brozovich, F., Heimberg, R., \& Gross, J. J. (2016). Group CBT versus MBSR for social anxiety disorder: A randomized controlled trial. Journal of Consulting and Clinical Psychology, 84(5), 427. 10.1037/ccp0000092

Gotink, R. A., Chu, P., Busschbach, J. J. V., Benson, H., Fricchione, G. L., \& Hunink, M. G. M. (2015). Standardised mindfulness-based interventions in healthcare: An overview of 
systematic reviews and meta-analyses of RCTs. PLoS ONE 10, 4. 10.1371/journal. pone. 0124344

Greenland, S. (1987). Quantitative methods in the review of epidemiologic literature. Epidemiologic Reviews, 9, 1-30. 10.1093/oxfordjournals.epirev.a036298

Hedges, L. V. (1994). Fixed effects models. In H. Cooper, \& L. V. Hedges (eds.), The handbook of research synthesis (pp. 285-299). New York, NY: Russell Sage Foundation.

Heimberg, R. G., \& Becker, R. G. (2002). Cognitive-behavioral group therapy for social phobia: Basic mechanisms and clinical strategies. New York, NY: Guilford Press.

Hofmann, S. G., \& DiBartolo, P. M. (Eds.). (2014). Social anxiety: Clinical, developmental, and social perspectives (3rd ed.). Boston, MA: Academic Press.

Hoge, E. A., Bui, E., Marques, L., Metcalf, C. A., Morris, L. K., Robinaugh, D. J., ... Simon, N. M. (2013). Randomized controlled trial of mindfulness meditation for generalized anxiety disorder: Effects on anxiety and stress reactivity. Journal of Clinical Psychiatry, 74(8), 786792. 10.4088/JCP.12m08083

Hougaard, E. (2006). Kognitiv behandling af panikangst og socialfobi: En vejledning for klienter og behandlere [Cognitive behavioural treatment of panic disorder and social phobia: A guideline for clients and therapists]. Copenhagen, Denmark: Dansk Psykologisk Forlag.

Houghton, V. (2008). Quantitative study of the effectiveness of mindfulness-based stress reduction treatment, using an internet-delivered self-help program, for women with generalized anxiety disorder (Doctoral dissertation). Retrieved from ProQuest Dissertations and Theses (Accession Order No. AAT 3310709).

Kabat-Zinn, J. (2003), Mindfulness-based interventions in context: Past, present, and future. Clinical Psychology: Science and Practice, 10(2), 144-156.

Kabat-Zinn, J., \& Santorelli, S. (1993). Mindfulness-based stress reduction professional training resource manual (Unpublished manuscript).

Knight, R. W., Bean, J., Wilton, A. S., \& Lin, E. (2015). Cost-effectiveness of the mindfulnessbased stress reduction methodology. Mindfulness, 6(6), 1379-1386. 10.1007/s12671-0150408-5

* Kocovski, N. L., Fleming, J. E., Hawley, L. L., Huta, V., \& Antony, M. M. (2013). Mindfulness and acceptance-based group therapy versus traditional cognitive behavioral group therapy for social anxiety disorder: A randomized controlled trial. Behaviour Research and Therapy, 51(12), 889-898. 10.1016/j.brat.2013.10.007

Kroenke, K., Spitzer, R. L., Williams, J. B., Monahan, P. O., \& Löwe, B. (2007). Anxiety disorders in primary care: Prevalence, impairment, comorbidity, and detection. Annals of Internal Medicine, 146(5), 317-325. 10.7326/0003-4819-146-5-200703060-00004

Maynard, B. R., Peters, K. E., Vaughn, M. G., \& Sarteschi, C. M. (2013). Fidelity in afterschool program intervention research: A systematic review. Research on Social Work Practice, 23(6), 613-623. 10.1177/1049731513491150

Moore, A. W., Gruber, T., Derose, J., \& Malinowski, P. (2012). Regular, brief mindfulness meditation practice improves electrophysiological markers of attentional control. Frontiers in Human Neuroscience, 6, 18. 10.3389/fnhum.2012.00018

Naleppa, M. J., \& Cagle, J. G. (2010). Treatment fidelity in social work intervention research: A review of published studies. Research on Social Work Practice, 20(6), 674-681. 10.1177/ 1049731509352088

* Piet, J., Hougaard, E., Hecksher, M. S., \& Rosenberg, N. K. (2010). A randomized pilot study of mindfulness-based cognitive therapy and group cognitive-behavioral therapy for young adults with social phobia. Scandinavian Journal of Psychology, 51(5), 403-410.

Rhodes, A. (2014). Yoga for traumatic stress: A three paper dissertation (Doctoral dissertation). Retrieved from ProQuest Dissertations and Theses (Accession Order No. AAT 3629601). 
Segal, Z. V., Williams, J. M. G., \& Teasdale, J. D. (2002). Mindfulness-based cognitive therapy for depression: A new approach to relapse prevention. New York, NY: Guilford.

Snyder, C., \& Lopez, S. (2011). Positive psychology: The scientific and practical explorations of human strengths. Thousand Oaks, CA: Sage Publications.

Somers, J. M., Goldner, E. M., Waraich, P., \& Hsu, L. (2006). Prevalence and incidence studies of anxiety disorders: A systematic review of the literature. Canadian Journal of Psychiatry, 51(2), 100-113. 10.1177/070674370605100206

* Sundquist, J., Lilja, Å., Palmér, K., Memon, A. A., Wang, X., Johansson, L. M., \& Sundquist, K. (2015). Mindfulness group therapy in primary care patients with depression, anxiety and stress and adjustment disorders: Randomised controlled trial. British Journal of Psychiatry, 206(2), 128-135. 10.1192/bjp.bp.114.150243

Torgerson, C. J. (2006). Publication bias: The Achilles' heel of systematic reviews? British Journal of Educational Studies, 54(1), 89-102.

Trowbridge, K., \& Lawson, L. M. (2016). Mindfulness-based interventions with social workers and the potential for enhanced patient-centered care: A systematic review of the literature. Social Work in Health Care, 55(2), 101-124. 10.1080/00981389.2015.1094165

Wittchen, H.-U. (2002), Generalized anxiety disorder: Prevalence, burden, and cost to society. Depression and Anxiety, 16(4), 162-171. 10.1002/(ISSN)1520-6394

Woodward, L. J., \& Fergusson, D. M. (2001). Life course outcomes of young people with anxiety disorders in adolescence. Journal of the American Academy of Child \& Adolescent Psychiatry, 40(9), 1086-1093. 10.1097/00004583-200109000-00018 